\title{
FORMAÇÃO DE MUDAS DE NIM COM APLICAÇÃO DE BIOFERTILIZANTE BOVINO SUBMETIDO À DRENAGEM E ESTRESSE SALINO
}

\author{
FORMATION OF NEEM SEEDLINGS WITH APPLICATION OF BOVINE \\ BIOFERTILIZER SUBJECTED TO DRAINAGE AND SALINE STRESS*
}

\section{Francisco Oliveira MESQUITA ${ }^{1}$; Lourival Ferreira CAVALCANTE ${ }^{2}$; Járisson Cavalcante NUNES ${ }^{3}$; Antonio Gustavo LUNA SOUTO ${ }^{4}$; Reinaldo Ferreira MEDEIROS ${ }^{5}$; Rummenigge Macêdo RODRIGUES ${ }^{3}$}

1. Estudante de Pós Graduação em Manejo de Solo e Água, Universidade Federal Rural do Semi-árido - UFERSA, Mossoró, RN, Brasil. mesquitaagro@yahoo.com.br; 2. Professor Adjunto, Universidade Federal da Paraíba - UFPB, Departamento de Solos e Engenharia Rural, pesquisador do INCTSal; Areia, PB, Brasil; 3. Departamento de Ciência do Solo - UFPB, Areia, PB, Brasil; 4. Universidade Federal de Viçosa, Departamento de Solos e Nutrição de plantas, Viçosa, MG, Brasil; 5. Departamento de Fitotecnia/CCA - UFPB, Areia, PB, Brasil;

RESUMO: Diversos fatores podem influenciar a formação de mudas. Entre as causas de insucesso, encontramse a dificuldade de manutenção de drenagem e qualidade da água de irrigação. O objetivo do trabalho foi avaliar os efeitos do biofertilizante bovino e salinidade da água de irrigação na formação de mudas de nim. O delineamento experimental foi em blocos casualizados, com os tratamentos arranjados no esquema fatorial $5 \times 2 \times 2$, com quatro repetições, referente aos níveis de salinidade da água de irrigação de 0,$5 ; 1,5 ; 3,0 ; 4,5$ e $6,0 \mathrm{dS} \mathrm{m}^{-1}$, no solo sem e com biofertilizante bovino, sem e com drenagem. As variáveis analisadas foram emergência de plântulas, número de folhas, diâmetro caulinar e área foliar. O biofertilizante bovino depois de diluído em água não salina $\left(0,49 \mathrm{dS} \mathrm{m}{ }^{-1}\right)$ e não clorada na razão de $1: 1$, foi aplicado uma única vez, dois dias antes da semeadura, ao nível de $10 \%$ do volume do substrato. A irrigação das plantas com cada tipo de água foi feita diariamente fornecendo um volume de água suficiente para elevar a umidade do solo para o nível mais próxima da capacidade de campo. Pelos resultados, com o aumento da salinidade das águas houve reduções no crescimento das plantas em até $28 \%$, mas o biofertilizante bovino e a drenagem do solo proporcionaram melhores condições de crescimento das mudas.

PALAVRAS-CHAVE: Azadirachta indica A. Juss. Biofertilização. Salinização.

\section{INTRODUÇÃO}

O nim (Azadirachta indica A. Juss), árvore da família Meliaceae, é conhecido principalmente na Índia, por sua ação medicinal e nas últimas décadas seu estudo vem sendo difundido devido à presença de substâncias inseticidas (DEBASHRI; TAMAL, 2012). Ao contrário da vasta bibliografia a respeito da biologia e das características inseticidas do nim, são raros os registros de estudos sobre o efeito da salinidade no crescimento desta espécie exótica.

No sistema de produção de mudas de boa qualidade devem-se adotar metodologias eficientes e, se possível, de baixo custo. Nessa fase fonológica e mesmo considerando que o nim durante o primeiro ano, é moderadamente tolerante à salinidade, isto é, pode sobreviver em níveis salinos de até $3 \mathrm{dS}$ m-1 (AYERS; WESTCOT, 1999). Acima destes valores, a planta pode ter seu crescimento inibido pela salinidade ou sodicidade e por outras limitações como a carência de água em termos de quantidade e de qualidade (FREIRE et al., 2010; FREIRE et al., 2014a).
Esta meliácea é utilizada em diversos programas de reflorestamento no Sudeste asiático e na África, com o intuito de recuperar áreas degradadas, visto que esta planta apresenta capacidade para crescer com poucas exigências tornando-se uma espécie indicada para reflorestamento em áreas degradadas (AMORIM et al., 2012). De acordo Girish e Shankara (2008) esta planta possui capacidade de adaptação a uma vasta gama de fatores climáticos, topográficos e edáficos (KARAN et al., 2012).

Sob condições salinas elevadas, de acordo com Lucak et al. (2012), é difícil cultivar ou aumentar a produtividade de muitas culturas em períodos de estresse hídrico, principalmente quando associado a temperaturas altas. Esses processos levam, consequentemente, a um aumento nos teores de sais do solo. Nesse sentido, as formas de minimizar os efeitos deletérios da salinidade são: por meio da lixiviação dos sais solúveis da zona radicular, onde para tal, emprega-se uma lâmina d'água com volume suficiente; por meio da utilização de biofertilizantes bovinos fornecido ao solo na forma líquida. Com relação ao primeiro 
método, deve haver certa preocupação com a água utilizada nos sistemas, pois, sua má qualidade causa degradação dos solos devido o excesso de sais. Já o segundo caso, embora seja mais tradicionalmente aplicado como agente de controle de pragas e doenças (PATIL et al., 2010; PEREIRA et al., 2012), vem sendo empregado com mais frequência na agricultura como método alternativo para atenuação dos efeitos salinos e que tem demonstrado resultados expressivos (MEDEIROS et al., 2011; FREIRE et al., 2014b).

Ainda com relação ao método da lavagem do solo, toma-se como primeiro requisito para a recuperação de um solo afetado por sais especialmente aqueles afetados por águas salinas de irrigação - a realização de uma drenagem adequada por meio de lâminas de lavagens. Em um solo com boa drenagem a salinidade pode ser reduzida para um nível tolerável. A quantidade da água necessária para realizar a lavagem de sais do perfil de solo é determinada em função do nível inicial da salinidade do solo, do nível final desejado, das características físicas, da profundidade (depende da cultura a ser explorada) e das demais propriedades do solo a ser recuperado. Além disso, depende do método de aplicação da lavagem do solo (DIAS; BLANCO, 2010; LIMA et al., 2010).

Abordando o método de aplicação de biofertilizantes, ao apreciar a ação positiva do biofertilizante bovino na melhoria edáfica em termos de aeração, dinâmica de ar e água no solo (MAVIA et al., 2012), na possibilidade das substâncias complexadas oriundas da matéria orgânica mitigarem os efeitos depressivos da salinidade das águas às plantas (AIDYN et al., 2012). Ao consideram também que a salinidade das águas dos mananciais de regiões semiáridas do Brasil, em geral, proporcionam restrição à grande maioria das culturas como registrado em plantas de maracujazeiro amarelo (AYERS; WESTCOT, 1999; MESQUITA et al., 2012), o emprego do respectivo insumos orgânicos devem inibir a ação salina das águas e estimular o crescimento inicial das plantas de nim, durante a formação de mudas (FREIRE et al., 2014a).

Nesse sentido, conduziu-se um experimento, com objetivo de avaliar o desempenho de mudas de nim submetidas sobre diferentes níveis de salinidade da água de irrigação no solo com biofertilizante bovino e drenagem do solo.

\section{MATERIAL E MÉTODOS}

O experimento foi conduzido em casa de vegetação do Departamento de Solos e Engenharia Rural do Centro de Ciências Agrárias da Universidade Federal da Paraíba, Areia, Paraíba, Brasil, no período de janeiro a junho de 2010.

O clima da região segundo a classificação de Köppen é do tipo As' (quente e úmido), com precipitação média anual de $1200 \mathrm{~mm}$, temperatura média da região $24,7{ }^{\circ} \mathrm{C}$, umidade relativa média de $71,9 \%$.

A temperatura média no período de realização do experimento no mês mais quente situou-se em torno de $32,45{ }^{\circ} \mathrm{C}$ fora e $43,91{ }^{\circ} \mathrm{C}$ no interior do abrigo telado; já no mês mais frio, os valores variaram de $26,91{ }^{\circ} \mathrm{C}$ fora e $31,68^{\circ} \mathrm{C}$ dentro do ambiente telado, com umidade relativa do ar no mês mais quente de $58 \%$ fora e $49 \%$ dentro do ambiente telado; no mês mais frio $82 \%$ fora e $59 \%$ dentro do abrigo telado.

$\mathrm{O}$ solo da área experimental foi caracterizado como LATOSSOLO Vermelho Amarelo distrófico de textura arenosa, não salino, coletado nos primeiros $20 \mathrm{~cm}$ de profundidade. Após coletadas as amostras foram transportadas para o laboratório de DSER/CCA/UFPB, postas a secarem ao ar e depois passadas em peneira de 2 $\mathrm{mm}$ de malha e caracterizadas fisicamente em termos de areia, silte e argila, densidade do solo e das partículas, também quanto à fertilidade, empregando as metodologias compiladas pela Embrapa (1997). Foram caracterizadas também quanto à salinidade do extrato de saturação conforme Richards (1954), cujos resultados estão indicados na (Tabela 1).

Tabela 1. Caracterização física e química quanto à fertilidade e salinidade do solo nos primeiros $20 \mathrm{~cm}$ de profundidade.

\begin{tabular}{lclclc}
\hline $\begin{array}{c}\text { Atributos } \\
\text { Físicos }\end{array}$ & Valor & $\begin{array}{c}\text { Atributos da } \\
\text { Fertilidade }\end{array}$ & Valor & $\begin{array}{c}\text { Atributos da } \\
\text { Salinidade }\end{array}$ & Valor \\
\hline $\mathrm{Ds}\left(\mathrm{g} \mathrm{cm}^{-3}\right)$ & 1,24 & $\mathrm{pH} \mathrm{em} \mathrm{água}(1: 2,5)$ & 5,08 & $\left.\mathrm{CEes}(\mathrm{dS} \mathrm{m})^{-1}\right)$ & 0,75 \\
$\mathrm{Dp}\left(\mathrm{g} \mathrm{cm}^{-3}\right)$ & 2,78 & $\mathrm{MO}\left(\mathrm{g} \mathrm{Kg}^{-1}\right)$ & 18,31 & $\mathrm{pH}$ & 6,71 \\
$\mathrm{Pt}\left(\mathrm{m}^{3} \mathrm{~m}^{-3}\right)$ & 0,54 & $\mathrm{P}\left(\mathrm{mg} \mathrm{dm}^{-3}\right)$ & 1,82 & $\mathrm{Ca}^{2+}\left(\mathrm{mmol}_{\mathrm{c}} \mathrm{L}^{-1}\right)$ & 1,72 \\
Areia $\left(\mathrm{g} \mathrm{kg}^{-1}\right)$ & 557 & $\mathrm{~K}^{+}\left(\mathrm{mg} \mathrm{dm}^{-3}\right)$ & 45,01 & $\mathrm{Mg}^{2+}\left(\mathrm{mmol}_{\mathrm{c}} \mathrm{L}^{-1}\right)$ & 0,67 \\
Silte $\left(\mathrm{g} \mathrm{kg}^{-1}\right)$ & 63 & $\mathrm{Ca}^{+2}\left(\mathrm{cmol}_{\mathrm{c}} \mathrm{dm}^{-3}\right)$ & 0,38 & $\mathrm{Na}^{+}\left(\mathrm{mmol}_{\mathrm{c}} \mathrm{L}^{-1}\right)$ & 0,25 \\
\hline
\end{tabular}




\begin{tabular}{|c|c|c|c|c|c|}
\hline Argila $\left(\mathrm{g} \mathrm{kg}^{-1}\right)$ & 380 & $\mathrm{Mg}^{+2}\left(\mathrm{cmol}_{\mathrm{c}} \mathrm{dm}^{-3}\right)$ & 0,27 & $\mathrm{~K}^{+}\left(\mathrm{mmol}_{\mathrm{c}} \mathrm{L}^{-1}\right)$ & 110 \\
\hline Ada $\left(\mathrm{g} \mathrm{kg}^{-1}\right)$ & 26 & $\mathrm{Na}^{+}\left(\mathrm{cmol}_{\mathrm{c}} \mathrm{dm}^{-3}\right)$ & 0,11 & $\mathrm{Cl}^{-}\left(\mathrm{mmol}_{\mathrm{c}} \mathrm{L}^{-1}\right)$ & 4,17 \\
\hline $\mathrm{GF}(\%)$ & 93,26 & $\mathrm{H}^{+}+\mathrm{Al}^{+3}\left(\mathrm{cmol}_{\mathrm{c}} \mathrm{dm}^{-3}\right)$ & 5,64 & $\mathrm{CO}_{3}{ }^{2-}\left(\mathrm{mmol}_{\mathrm{c}} \mathrm{L}^{-1}\right)$ & - \\
\hline ID (\%) & 6,84 & $\mathrm{Al}^{+3}\left(\mathrm{cmol}_{\mathrm{c}} \mathrm{dm}^{-3}\right)$ & 0,87 & $\mathrm{HCO}_{3}^{-}\left(\mathrm{mmol}_{\mathrm{c}} \mathrm{L}^{-1}\right)$ & 1,51 \\
\hline $\mathrm{U}_{\mathrm{cc}}\left(\mathrm{g} \mathrm{kg}^{-1}\right)$ & 14,84 & $\mathrm{SB}\left(\mathrm{cmol}_{\mathrm{c}} \mathrm{dm}^{-3}\right)$ & 0,88 & $\mathrm{SO}_{4}{ }^{2-}\left(\mathrm{mmol}_{\mathrm{c}} \mathrm{L}^{-1}\right)$ & 2,21 \\
\hline $\mathrm{U}_{\mathrm{pmp}}\left(\mathrm{g} \mathrm{kg}^{-1}\right)$ & 4,54 & $\operatorname{CTC}\left(\mathrm{cmol}_{\mathrm{c}} \mathrm{dm}^{-3}\right)$ & 6,52 & $\operatorname{RAS}\left(\mathrm{mmol} \mathrm{L}^{-1}\right)^{1 / 2}$ & 0,19 \\
\hline $\operatorname{Ad}\left(\mathrm{g} \mathrm{kg}^{-1}\right)$ & 9,34 & $\mathrm{~V}(\%)$ & 13,49 & $\operatorname{PST}(\%)$ & 1,68 \\
\hline
\end{tabular}

$\mathrm{Ds}=$ Densidade do solo; $\mathrm{Dp}=$ Densidade de partícula; $\mathrm{Pt}=$ Porosidade total; $\mathrm{Ada}=$ Argila dispersa em água; $\mathrm{GF}=\mathrm{Grau}$ de floculação; $\mathrm{ID}=$ Índice de dispersão; $\mathrm{U}_{\mathrm{cc}}$ e $\mathrm{U}_{\mathrm{pmp}}=$ respectivamente umidade do solo às tensões de $-0,01$ e $-1,5 \mathrm{MPa} ; \mathrm{Ad}=$ Águas disponível; $\mathrm{MO}=$ Matéria orgânica; $\mathrm{SB}=$ Soma de bases $\left(\mathrm{Na}^{+}+\mathrm{K}^{+}+\mathrm{Ca}^{2+}+\mathrm{Mg}^{2+}\right)$; CTC $=$ Capacidade de troca catiônica $=\mathrm{SB}+\left(\mathrm{H}^{+}+\mathrm{Al}^{3+}\right)$; $\mathrm{V}=\mathrm{Valor}$ de saturação por bases $(100 \times \mathrm{SB} / \mathrm{CTC}) ;$ CEes = Condutividade elétrica do extrato de saturação; RAS = Relação de adsorção de sódio = $\mathrm{Na}^{+} \div\left[\left(\mathrm{Ca}^{2+}+\mathrm{Mg}^{2+}\right) / 2\right]^{1 / 2} ;$ PST $=$ Percentagem de sódio trocável $\left(100 \mathrm{x} \mathrm{Na}^{+} / \mathrm{CTC}\right)$.

Utilizou-se vasos plásticos com diâmetro de $26,11 \mathrm{~cm}$ de base e $35 \mathrm{~cm}$ de altura, com capacidade máxima para $20 \mathrm{dm}^{-3}$. Contudo, Cada unidade experimental continha $15 \mathrm{dm}^{-3}$ de substrato. Na base do vaso foi colocado uma camada de $2 \mathrm{~cm}$ de espessura de brita grossa $\left(\mathrm{n}^{\circ} .20\right)$ e uma outra camada de mesma espessura de areia fina lavada. Cada unidade experimental foi constituída por apenas uma planta de nim por vaso plástico obedecendo ao sistema de padronização de mudas. Esse mesmo sistema, que é tido como referencia principalmente para culturas silvestres, também foi adotado por (DINIZ et al., 2013).

Os tratamentos foram distribuídos em blocos casualizados, com quatro repetições, em arranjo fatorial $5 \times 2 \times 2$, referente a cinco níveis de salinidade da água de irrigação: 0,$5 ; 1,5 ; 3,0 ; 4,5$ e $6,0 \mathrm{dS} \mathrm{m}^{-1}$, no solo sem e com biofertilizante bovino na forma líquida, sem e com de drenagem do solo para lixiviação dos sais. $\mathrm{O}$ valor da condutividade elétrica de cada tipo de água usada para irrigação foi obtido pela diluição de uma água de barragem fortemente salina $\left(12,4 \mathrm{dS} \mathrm{m}^{-1}\right)$ oriundo do açude jacaré localizado no município de Remígio, PB, e, dessa forma foi adicionada água não salina de condutividade elétrica $\left(0,49 \mathrm{dS} \quad \mathrm{m}^{-1}\right)$ como procederam também Medeiros et al. (2011) e Mesquita et al. (2012).

A irrigação até os primeiros 63 dias após a emergência foi feita diariamente através do processo de pesagem repondo o volume de água evapotranspirado no dia anterior de modo a manter o solo com umidade ao nível de capacidade de campo. A partir dos 63 dias após a emergência e a cada 15 dias, efetuava-se a lavagem do solo com cada tipo de água utilizada na irrigação das plantas. Em cada intervalo de 15 dias, nos primeiro quatorze dias a reposição de água era feita, como inicialmente, pela diferença de massa dos tratamentos entre o dia atual e o anterior, para manutenção do solo com umidade na capacidade de campo. No décimo quinto dia, nos tratamentos com drenagem fornecia-se gradualmente registrando o volume aplicado até o início da drenagem dos vasos, em seguida adicionava-se mais $10 \%$ do volume irrigado correspondente a lâmina de lavagem para a lixiviação dos sais (AYERS; WESTCOT, 1999).

O sistema de drenagem foi iniciado aos 63 dias após a emergência das plântulas e feita a cada quinzena. A água coletada pelo sistema descrito a pouco, era aquela correspondente à aplicação no sétimo dia, onde se fornecia água até o solo iniciar a drenagem. Nesse ponto, mais um volume de cada tipo de água correspondente a $10 \%$ do volume aplicado era adicionado para a lavagem do solo e a lixiviação dos sais. Após cessar a drenagem, o volume lixiviado foi medido e em cada tratamento foi quantificado o volume de água adicionado, percolado, o volume de água retido no solo, o $\mathrm{pH}$ e a condutividade elétrica do material percolado. Em seguida somavam-se ao volume total aplicado no sétimo dia com os volumes fornecidos diariamente e este era o volume utilizado no cálculo do consumo semanal das plantas. A água de drenagem caracterizou-se como material potencialmente poluente em termos da concentração de sais solúveis, tornando-se impróprio para reutilização agrícola.

O biofertilizante foi obtido a partir da mistura de partes iguais de esterco fresco de bovino e água (não salina e não clorada), em biodigestor sob fermentação anaeróbica, durante 30 dias, conforme procedeu (SANTOS; AKIBA, 1992). O biodigestor consistia em um recipiente plástico com capacidade para 200 litros mantido sempre fechado hermeticamente. Dois dias antes da semeadura, o biofertilizante foi diluído em água na proporção 1:1 e aplicado em volume equivalente a $10 \%$ do volume do substrato $\left(15 \mathrm{dm}^{-3}\right)$. Para a manutenção sistema de biodigestão, conectou-se a extremidade de uma mangueira de $4 \mathrm{~mm}$ de diâmetro na base superior do biodigestor e a outra extremidade foi imersa em um garrafa tipo PET 2 L contendo água. Por ser aplicado na forma líquida, o biofertilizante foi avaliado como se fosse água para irrigação, conforme metodologia sugerida por Richards 
(1954), e apresentou os seguintes valores: $\mathrm{Ca}^{2+}=$ $1,17, \mathrm{Mg}^{2+}=0,68, \mathrm{Na}^{+}=2,47, \mathrm{~K}^{+}=0,16, \mathrm{Cl}^{-}=3,47$; $\mathrm{HCO}_{3}=0,28, \quad \mathrm{SO}_{4}^{-2}=0,76 \quad \mathrm{mmol}_{\mathrm{c}} \mathrm{L}^{-1}$ e condutividade elétrica a $25^{\circ} \mathrm{C}=3,33 \mathrm{dS} \mathrm{m}^{-1}$ e $\mathrm{pH}=$ 6,71 .

Em cada unidade experimental foram semeadas seis sementes de nim (Azadirachta indica A. Juss) com viabilidade de $89 \%$. Após a semeadura foi feito o monitoramento para registro da primeira contagem das plântulas normais emergidas e realizadas contagens diárias até $o$ final da emergência aos 15 DAS para avaliação do índice de velocidade de emergência.

Aos 30 dias após a emergência, foi realizado desbaste das plântulas deixando-se apenas uma plântula, ou seja, a mais vigorosa em cada vaso. Ao final do experimento aos $180 \mathrm{DAE}$, foi contado o número de folhas e medido o diâmetro caulinar com paquímetro digital, obtida a área foliar por meio de fotografia digital e depois se utilizou o programa computacional Sigma Scan Pro v. 5.0 para determinar a área em $\mathrm{cm}^{2}$.

Os dados de emergência de plântulas, diâmetro do caule, número de folhas e área foliar foram submetidos à análise de variância pelo teste "F" e regressão polinomial para os níveis de salinidade (BANZATTO; KRONKA, 2008). Para o processamento dos dados foi utilizado o software SAS (SAS INSTITUTE Inc, 2003).

\section{RESULTADOS E DISCUSSÃO}

O aumento da salinidade das águas inibiu a emergência das plântulas, mas em menor proporção nos tratamentos com biofertilizante bovino. Ao final da emergência aos 15 dias até a estabilização das plântulas, como demonstrados na (Figura 1), observa-se incrementos percentuais de plantas emergidas variando de 41,67 até $49,14 \%$, correspondeente aos valores estimados de 0,58 e $1,14 \mathrm{dS} \mathrm{m}^{-1}$, respectivamente no solo sem e com biofertilizante. Comparando os tratamentos com o insumo orgânico avaliados no solo com o incremento salino da água de irrigação de 0,5 para 6 dS $\mathrm{m}^{-1}$, a emergência de plântulas provocou declínios de 50,31 para $27,73 \%$ referente a salinidade da água.

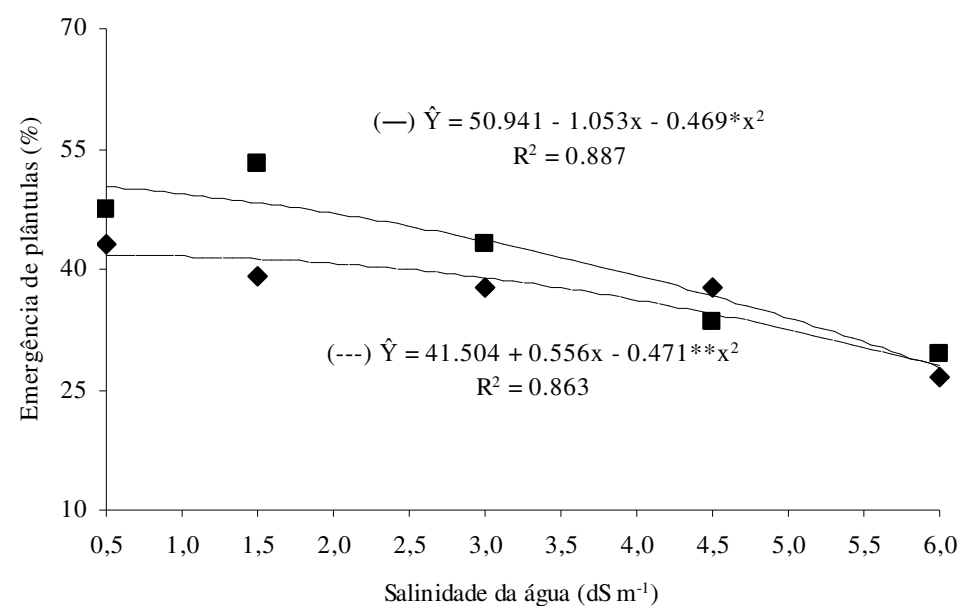

Figura 1. Emergência de plântulas de nim no substrato sem (---) e com (-) biofertilizante bovino submetido à salinidade da água de irrigação no período de 15 DAS.

Essa resposta pode ser provavelmente pela componente osmótica resultante de elevadas concentrações de sais dissolvidos na solução do solo, os quais reduzem o potencial osmótico da solução diminuindo, consequentemente, a disponibilidade de água para as plantas (MUNNS; TESTER, 2008; GARCÍA et al., 2011; PEREIRA et al., 2012).

No solo sem a drenagem agrícola, os valores referentes ao diâmetro do caule das mudas de nim variaram de 3,30 até 4,91 $\mathrm{mm}$, isto é, no solo sem e com biofertilizante bovino, respectivamente (Fig. 2D1). No solo com drenagem (Fig. 2D2), as mudas de nim tiveram diâmetro caulinar aumentado de 3,76 para até $5,20 \mathrm{~mm}$, ambas as situações, foram no solo sem e com insumo orgânico, correspondendo a menor salinidade da água de irrigação de $0,5 \mathrm{dS} \mathrm{m}^{-1}$. Percentualmente as mudas no solo com biofertilizante superou em até $6,12 \%$ no diâmetro caulinar quanto comparada aos substratos sem o composto orgânico e sem drenagem agrícola. 
D1

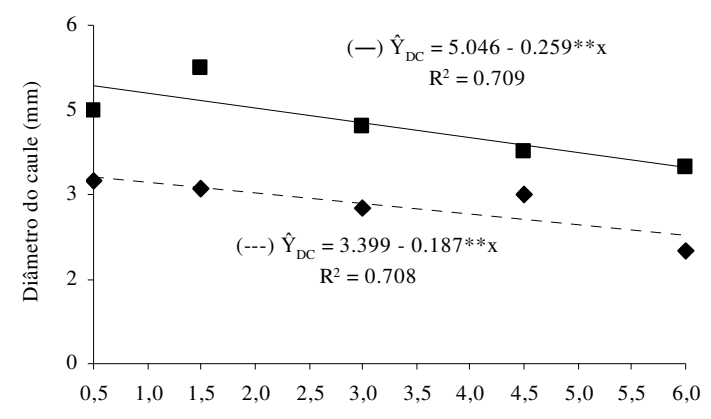

Salinidade da água $\left(\mathrm{dS} \mathrm{m}^{-1}\right)$
D2

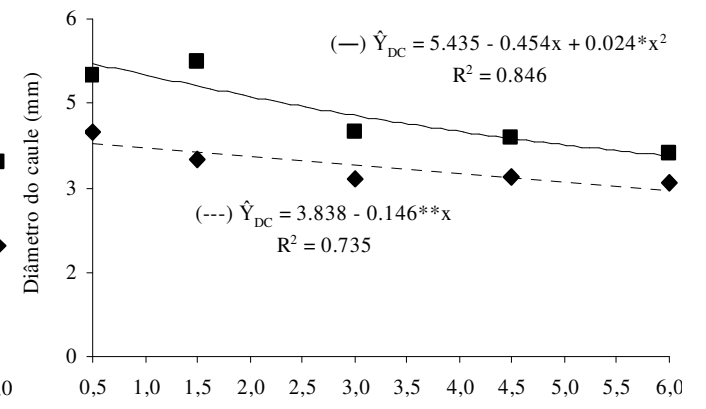

Figura 2. Diâmetro do caule de mudas de nim no solo sem (---) e com (-) biofertilizante bovino, na ausência (D1) e presença (D2) drenagem agrícola em função da salinidade da água de irrigação no período de 180 DAE.

Comparativamente, o nim comportou-se de forma semelhante ao tomateiro cereja (Solanum lycopersicon) estudado por Medeiros et al. (2011) e ao maracujazeiro amarelo (Passiflora edullis f. flavicarpa Deg.) observado por Campos et al. (2011) e Mesquita et al. (2012) em que, apesar do diâmetro do caule das plantas ser inibido com o aumento da salinidade das águas de irrigação, os resultados foram sempre superiores nos tratamentos com biofertilizante.

O número de folhas de plantas de nim avaliado no período de 180 DAS reduziu drasticamente da menor para maior condutividade elétrica da água de irrigação $\left(0,5\right.$ e $\left.6,0 \mathrm{dS} \mathrm{m}^{-1}\right)$, variando de 24 para 7 folhas planta $^{-1}$ no solo sem biofertilizante, e de 35 para até 25 folhas planta ${ }^{-1}$ no solo com o insumo orgânico (Figura 3).

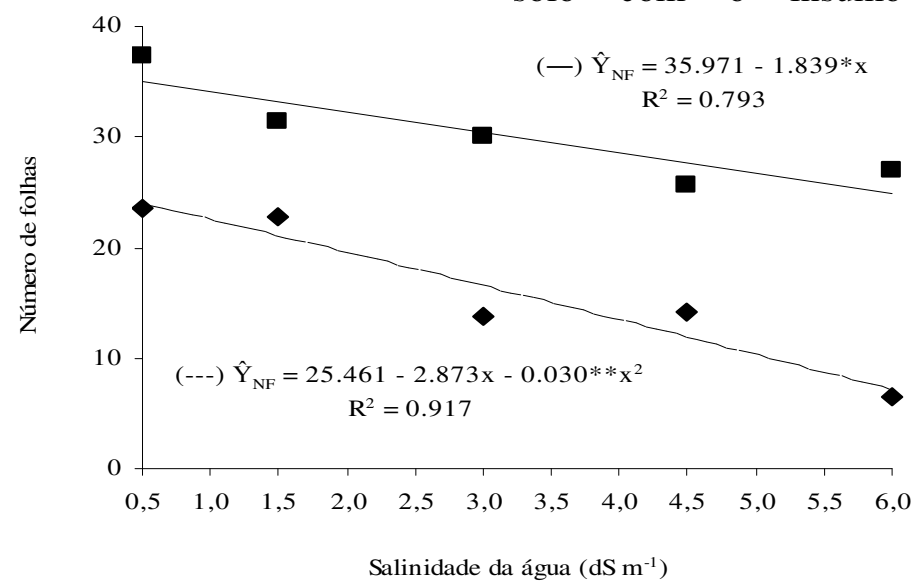

Figura 3. Número de folhas de mudas de nim avaliados no solo sem (---) e com (-) biofertilizante bovino em função da salinidade da água de irrigação no período de 180 DAE.

O aumento do estresse salino das águas ou do solo inibiu a emissão das folhas das plantas de nim refletindo-se negativamente na expansão da área foliar, resultando em declínios na taxa de fotossíntese líquida prejudicando os processos fisiológicos e bioquímicos das plantas em geral, inclusive no nim indiano como constatado por Diniz et al. (2013). Comparativamente as reduções são semelhantes às obtidas por Rebequi et al. (2009) e Mesquita et al. (2012) durante a formação de mudas de limão cravo e de maracujazeiro amarelo sob irrigação com águas salinas, com menores declínios nas plantas dos tratamentos com biofertilizante bovino.
O aumento da salinidade da água de 0,5 para $6,0 \mathrm{dS} \mathrm{m}{ }^{-1}$, inibiu a área foliar das plantas no solo sem drenagem de 702,74 a 227,92 e 962,05 até $658,62 \mathrm{~cm}^{2}$, com e sem biofertilizante bovino, respectivamente (Fig. 4D1).

Nas irrigações com as mesmas águas nos tratamentos com drenagem (Figura 4D2), os valores oscilaram de 939,95 para 515,08 e de 1272,75 para $871,12 \mathrm{~cm}^{2}$ no solo com e sem o insumo orgânico, e ambas as situações, os números correspondem a menor e maior salinidade da água de irrigação de 0,5 e $6,0 \mathrm{dS} \mathrm{m}^{-1}$. 

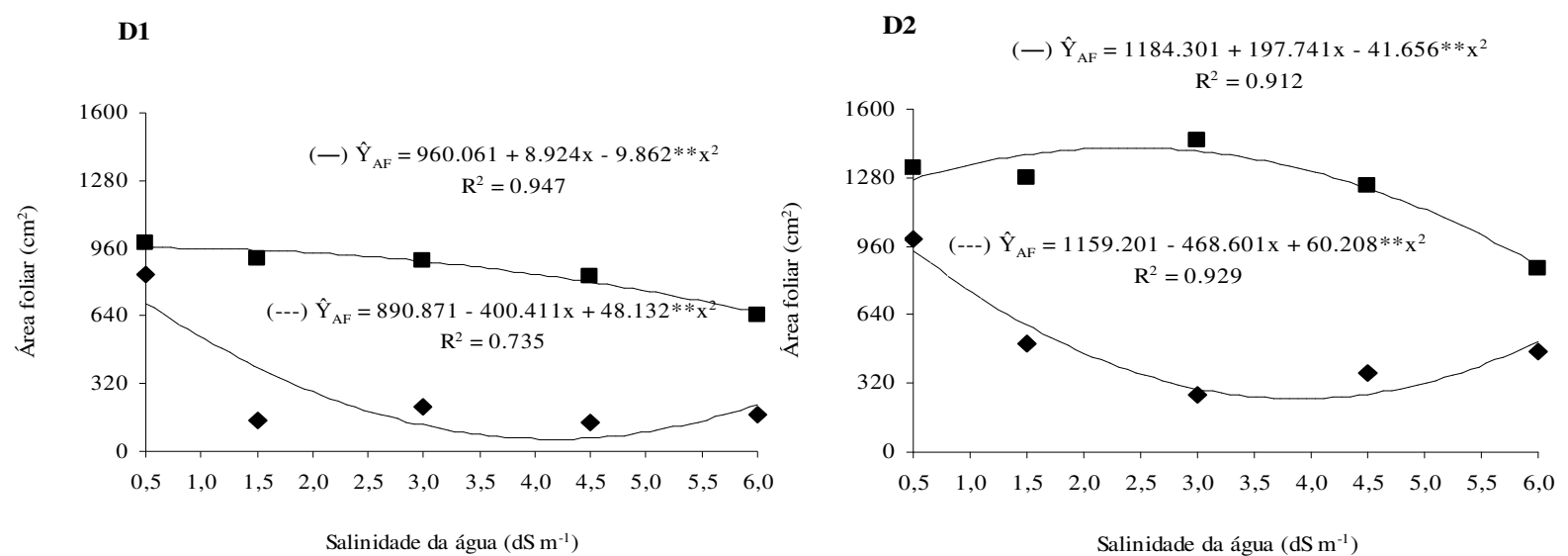

Figura 4. Área foliar de plantas de nim no substrato sem (---) e com (-) biofertilizante bovino, sem (D1) e com (D2) drenagem do solo em função da salinidade da água de irrigação no período de 180 DAE.

Essa situação, conforme Carneiro et al. (2007) e Mavia et al. (2012), evidencia o estrresse hídrico provocado pelo efeito osmótico da salinidade da água às plantas, principalmente nas plantas do solo sem biofertilizante e sem drenagem para lixiviação do excesso de sais açulados pelas águas de salinidade crescente.

\section{CONCLUSÕES}

$\mathrm{O}$ aumento da salinidade das águas inibiu a emergência das plântulas e o crescimento de plantas de nim.

O biofertilizante bovino proporcionou maior crescimento das plantas de nim em diâmetro caulinar, número de folhas e área foliar sob irrigação com águas salinas.

$\mathrm{O}$ uso da drenagem concomitantemente com o biofertilizante bovino beneficia o crescimento em diâmetro caulinar e área foliar em mudas de nim.

\section{AGRADECIMENTOS}

Ao Conselho Nacional de Desenvolvimento Científico e Tecnológico (CNPq), à Fundação de Amparo à Pesquisa do Estado da Paraíba e ao Instituto Nacional de Ciência e Tecnologia em Salinidade - (INCTSal), pelas concessões de bolsa de estudo e financiamento do projeto.

\begin{abstract}
Several factors may influence in formation of seedlings. Among the causes of failure find discovered the difficulty of maintain of the drainage and quality of irrigation water. The objective of wok was study or evaluate the effects of bovine biofertilizer and water salinity in the formation of neem seedlings. The experimental design was in randomized block, with the treatments arranged in factorial scheme $5 \times 2 \times 2$, with four repetitions, referring at the five salinity levels of irrigation water: $0.5,1.5,3.0,4.5$ and $6.0 \mathrm{dS} \mathrm{m}^{-1}$, in soil without and with bovine biofertilizer, in soil without and with soil drainage. The variables analyzed were: seedlings emergence, number of leaves, stem diameter and leaf area. The bovine biofertilizer after diluted in noon-saline water $\left(0,49 \mathrm{dS} \mathrm{m}^{-1}\right)$ e not chlorinated in reason to 1:1, was applied an once two days before sowing, at level to $10 \%$ of substrate volume. The plants were irrigated daily with each type of water in volume sufficient to increase the soil moisture for the level nearest of field capacity. By results, with the increasing of salinity waters there were reductions in plant growth up to $28 \%$, but the bovine biofertilizer and soil drainage provided better conditions for seedling growth.
\end{abstract}

KEYWORDS: Azadirachta indica. Biofertilization. Salinization.

\title{
REFERÊNCIAS
}

AMORIM, H. B.; FRANCELINO, M. R.; SALAMENE, S.; PEDREIRA, L. O. L.; ASSUMPÇÃO FILHO, L. I.; CAPITANO, R. C.; MOURA, T. A. Estimativa da área ocupada por reflorestamento no estado do Rio de Janeiro. Cerne, Lavras, v. 18, n. 1, p. 27-32, 2012. 
AIDYN, A.; KANT, C.; TURAN, M. Humic acid application alleviate salinity stress of bean (Phaseolus vulgaris L.) plants decreasing membrane leakage. African Journal of Agricultural Research, v. 7, n. 7, p. 1073-1086, 2012.

AYERS, R. S.; WESTCOT, D. W. A qualidade da água na agricultura. Trad. H. R. Gheyi et al., Campina grande: UFPB, (Estudos FAO: Irrigação e Drenagem, 29). 153p. 1999.

BANZATTO, D A; KRONKA, SN. Experimentação agrícola. 4. ed. Jaboticabal: UNESP, 247pp. 2008

CAMPOS, V. B.; CAVALCANTE, L. F.; CAMPOS, S. S. P.; CHAVES, L. H. G.; MESQUITA, F. O. Esterco bovino líquido em luvissolo sódico: I. Resposta biométrica e produtiva do maracujazeiro amarelo. Idesia, Arica, v. 29, n. 2, p. 59-67, 2011.

CARNEIRO, J. G. A.; BARROSO, D. G.; SOARES, L. M. S. Crescimento de mudas em raiz nua de Pinus taeda L., sob cinco espaçamentos no viveiro e seu desempenho no campo. Revista Brasileira Agrociência, v. 13, p. 305-310, 2007.

CAVALCANTE, L. F.; VIEIRA, M. S.; SANTOS, A. F.; OLIVEIRA, V. M.; NASCIMENTO, J. A. M. Água salina e esterco bovino líquido na formação de mudas de goiabeira cultivar Paluma. Revista Brasileira de Fruticultura, Jaboticabal, v. 32, p. 251-261, 2010.

DEBASHRI, M.; TAMAL, MONDAL. A review on efficacy of azadirachta indica a. juss based biopesticides: an indian perspective. Research Journal of Recent Sciences, India, v. 3, n. 1, p. 94-99, 2012.

DIAS, N. S.; BLANCO, F. F. Efeitos dos sais no solo e na planta. In: Manejo da salinidade na agricultura: Estudos básicos e aplicados. Instituto Nacional de Ciência e Tecnologia em salinidade. Fortaleza. 2010.

GIRISH K.; SHANKARA B. S. Neem - A Green Treasure. Electronic Journal of Biology, v. 4, n. 3, p. 102$111,2008$.

Empresa Brasileira de Pesquisa Agropecuária - EMBRAPA. Centro Nacional de Pesquisa de Solos. Manual de métodos de análise do solo. 2ed. Rio de Janeiro 212p. (Embrapa-CNPS. Documentos, 1). 1997.

FREIRE, A. L. O.; SOUSA FILHO, G. M.; MIRANDA, J. R. P.; SOUTO, P. C.; ARAÚJO, L. V. C. Crescimento e nutrição mineral do nim (Azadirachta indica A. Juss.) e cinamomo (Melia azedarach Linn.) submetidos à salinidade. Ciência Florestal, Santa Maria, v. 20, n. 2, p. 207-215, 2010.

FREIRE, A. L. O.; CAVALCANTE, L. F.; REBEQUI, A. M.; DIAS, T. J.; BREHM, M. A. S; SANTOS, J. B. Physical characteristics of fruit of yellow passion fruit produced in soil with bio-fertilizer, mulching and saline water. Idesia, Chile, v. 32, v. 1, p. 71-78, 2014a.

FREIRE, A. L. O.; CAVALCANTE, L. F.; REBEQUI, A. M.; DIAS, T. J.; BREHM, M. A. S; SANTOS, J. B. Quality of yellow passion fruit juice with cultivation using different organic sources and saline water. Idesia, Chile, v. 32, n. 1, p. 79-87, 2014b. http://dx.doi.org/10.4067/S0718-34292014000100009

GARCÍA, B. L.; ALCÁNTARA, L. P.; FERNÁNDEZ, J. L. M. Soil tillage effects on monovalent cations $\left(\mathrm{Na}^{+}\right.$ and $\mathrm{K}^{+}$) in vertisols soil solution. Catena, Amsterdam, v. 84, p. 61-69, 2011.

KARAN, R.; SUBUDHI, P. K. Approaches To Increasing Salt Tolerance In Crop Plants. Irrigation Science, New York, v. 30, n. 1, p. 63-88, 2012.

LIMA, V. A. de.; FARIAS, M. S. S. de.; BORGES JÚNIOR, J. C. F. Drenagem agrícola no manejo dos solos afetados por sais. In: Gheyi, H. R; DIAS, N. S; LACERDA, C. F. (Org.). Manejo da salinidade na agricultura: estudos básicos e aplicado. 1 ed. Fortaleza: Instituto Nacional de Ciência e Tecnologia em Salinidade, cap. 20, pp. 370-382. 2010. 
LUKAC, M.; PENSA, M.; SCHILLER, G. 'Tree Species' Tolerance to Water Stress, Salinity and Fire. Irrigation Science, New York, v. 212, n. 1, p. 247-261, 2012.

MAVIA, M. S.; MARSCHNERA, P.; CHITTLEBOROUGHC, D. J.; COXC, J. W.; SANDERMANE, J. Salinidade e sodicidade afetam a respiração do solo e da dinâmica da matéria orgânica dissolvida diferencialmente em solos de diferentes texturas. Soil Biology and Biochemistry, Elmsford, v. 45, n. 1, p. 813, 2012.

MEDEIROS, R. F.; CAVALCANTE, L. F.; MESQUITA, F. O.; RODRIGUES, R. M.; SOUSA, G. G.; DINIZ, A. A. Crescimento inicial do tomateiro-cereja sob irrigação com águas salinas em solo com biofertilizantes bovino. Revista Brasileira de Engenharia Agrícola e Ambiental, Campina Grande, v. 15, n. 5, p. 505-511, 2011.

DINIZ, B. L. M. T.; CAVALCANTE, L. F.; MESQUITA, F. O.; LIMA NETO, A. J.; NUNES, J. C.; DINIZ NETO, M. A. Crescimento inicial e consumo hídrico de nim submetido ao estresse salino e biofertilizante bovino. Agrária - Revista Brasileira de Ciências Agrárias, v. 8, n. 3, p. 470-475, 2013.

MUNNS, R.; TESTER, M. Mechanisms of salinity tolerance: Plant biology, Nova York, 59: 651-681. 2008.

PATIL, N. M. Biofertilizer effect on growth, protein and carbohydrate content in stevia rebaudiana var bertoni. Recent Research in Science and Technology, v. 2, n. 10, p. 42-44, 2010.

PEREIRA, M. R. R.; MARTINS, C. C.; SOUZA, G. S. F.; MARTINS, D. Influência do estresse hídrico e salino na germinação de Urochloa decumbens e Urochloa ruziziensis. Bioscience Journal, Uberlândia, v. 28, n. 4, p. 537-545, 2012.

REBEQUE, A. M.; CAVALCANTE, L. F.; NUNES, J. C.; DINIZ, A. A.; BREHM, M. A. S.; BECKMANNCAVALCANTE, M. Z. Produção de mudas de limão cravo em substrato com Biofertilizante bovino irrigado com águas salinas. Revista de Ciências Agrárias, Lisboa, v. 32 n. 2, p. 219-228, 2009.

RICHARDS, L. A. Diagnostico y rehabilitación de suelos salinos y sódicos. México: Departamento de Agricultura de los Estados Unidos de América, 174p (Manual de Agricultura, 60). 1954.

SANTOS, A. C. V.; AKIBA, F. Biofertilizante líquido: uso correto na agricultura alternativa. Seropédica: UFRRJ, Impr. Univ., 35p. 1996.

SANTOS, H. G.; JACOMINE, P. K. T.; ANJOS, L. H. C.; OLIVEIRA, V. A.; OLIVEIRA, J. B.; COELHO, M. R.; LUMBREBAS, J. F.; CUNHA, T. J. F. Sistema brasileiro de classificação de solos. 2ed. Rio de Janeiro: 306p. Embrapa Solos. 2006.

SAS Institute. SAS/ESTAT: user's guide: statistics version 9.1 Cary, 1 CD-ROM. 2003.

SEMIZ, G.; YURTSEVEN, E. I. Salinity Distrubution, Water Use Efficiency and Yield Response of Grafted and Ungrafted Tomato (Lycopersicon esculentum) Under Furrow and Drip Irrigation with Moderately Saline Water in Central Anatolian Condition".GOÜ, Ziraat Fakültesi Dergisi, v. 28, n. 2, p. 101-111, 2010.

YANG, J.; ZHANG, L.; HIRA, D.; FUKUZAKI, Y.; FURUKAWA, K. Anammox treatment of high-salinity wastewater at ambient temperature. Bioresource Technology, Essex, V. 102, p. 2367-2372, 2011.

http://dx.doi.org/10.1016/j.biortech.2010.10.101 